\title{
Food refusal in prisoners: a communication or a method of self-killing? The role of the psychiatrist and resulting ethical challenges
}

Bea Brockman St fames' Hospital, Portsmouth, Hampshire

\begin{abstract}
Food refusal occurs for a variety of reasons. It may be used as a political tool, as a method of exercising control over others, at either the individual, family or societal level, or as a method of self-harm, and occasionally it indicates possible mental illness. This article examines the motivation behind hunger strikes in prisoners. It describes the psychiatrist's role in assessment and management of prisoners by referring to case examples. The paper discusses the assessment of an individual's competence to commit suicide by starvation, legal restraints to intervention, practical difficulties and associated ethical dilemmas. Anecdotal evidence suggests that most prisoners who refuse food are motivated by the desire to achieve an end rather than killing themselves, and that hunger-strike secondary to mental illness is uncommon. Although rarely required, the psychiatrist may have an important contribution to make in the management of practical and ethical difficulties.
\end{abstract}

(Fournal of Medical Ethics 1999;25:451-456)

Keywords: Hunger-strike; prisoner; psychiatrist; competence; legal; ethical

\section{Introduction}

This article examines food refusal in prisoners. Food refusal is a communication. As such it may be a political statement, ${ }^{1}$ a method of exercising control or reducing tension, a variant of self-harm, a personal statement of distress, or part of a mental disorder. Such behaviour may be seen as manipulative and we must take care to decipher the communication and to be aware of the strength of our own subjective value judgments.

I shall cover prisoners' motivations for food refusal, the role of the psychiatrist, legal constraints and practical and ethical dilemmas: I will use examples from my clinical experience as a forensic psychiatrist who regularly visits prisons, to illustrate my points. In contrast to the hungerstrikers described by O'Connor and JohnsonSabine only one of the ten cases I have encountered in 15 years was mentally ill. ${ }^{1}$
The Prison Health Care Service consults psychiatrists for advice on diagnosis, treatment and management of some cases. In the course of such "liaison" work I am infrequently asked to see a prisoner who is refusing food and/or fluids. Brief episodes of food refusal by prisoners are frequent but referral to a psychiatrist is uncommon. Examples are drawn from remand and sentenced prisoners, asylum seekers and illegal immigrants. All cases have been modified to ensure individuals' anonymity. For clarity I shall refer to the prisoner as he and the practitioner as she. The issues are the same regardless of gender.

\section{Motivation for food refusal}

In assessing any "problem" behaviour it is important to remember that similar types of behaviour are not necessarily driven by similar motivation, even if they occur in specific situations.

\section{I) REMAND PRISONERS}

Remanded prisoners often exhibit brief periods of hunger-strike when they feel unfairly charged or angered by refusal of their bail application. When angered and in custody, individuals cannot employ their usual problem-solving tactics, such as walking away from the situation or verbal or physical confrontation. The need to express anger can precipitate extreme behaviours such as food refusal and "dirty" protest, that is refusal to use bathroom facilities. The behaviour is motivated by the individual's desire to effect a change in circumstances.

Example: I assessed a young, heavily tattooed white man with closely shaven hair who had refused food and drink for forty-eight hours and had threatened to kill himself. $\mathrm{He}$ was in a hospital-wing cell which had been stripped of all furniture apart from a mattress and blanket and dressed in a non-destructive suit. He was hostile, at first not wanting to talk to the "shrink". After I had explained my role, he agreed to talk to me but only to remonstrate about the injustice he was suffering. In his opinion he was unfairly charged 
for possession of firearms as he "only had half a shotgun". Enquiry revealed an extensive criminal history of acquisitive, assaultative, drug and weapon offences. He explained that his refusal to eat and drink was a protest, with the intention of obtaining release on bail. Examination revealed he was not suffering from mental disorder and was simply angry at loss of liberty and inability to express his autonomy. He could only exercise control over his situation by refusing to cooperate. His behaviour was instrumental - a means to an end.

\section{II) SENTENCED PRISONERS}

Sentenced prisoners, particularly young prisoners, and those receiving a first lengthy sentence can act in a similar way to those on remand by resorting to food refusal, which in this situation may be a variant of self-harm. Self-destructive behaviours, even those leading to grave risk to self, are not necessarily caused by mental illness. These behaviours are commonly used to reduce tension by impulsive, personality-disordered people and those emotionally immature for their chronological years. Some fulfil the diagnostic criteria for dissocial personality disorder (ICD-10 F60.2) ${ }^{2}$ and the legal criteria for psychopathic disorder (Mental Health Act, 1983). ${ }^{3}$ Their reckless behaviour is instrumental, a method of reducing tension or an attempt to precipitate change, rather than a serious desire to die.

Some sentenced prisoners are genuinely distressed by their offence and/or its consequences, for example, the killing of a spouse or receiving a lengthy or life sentence. A few choose to commit suicide by starvation as they are prevented from killing themselves by other physical means. Suicide may be chosen as a method of escaping punishment, a means to exercise autonomy, or a method of self-killing secondary to grief or guilt.

Example: a middle-aged white man refused nourishment for several days after receiving a life sentence for manslaughter. He felt he had no right to live after killing his wife. He had chosen to kill himself by starvation as he was prevented from using other physical methods by strict observation following a previous suicide attempt. In his distress he had also refused to allow any family member to visit him for some weeks. He was assessed repeatedly over two weeks and although greatly distressed and grieving he had neither a depressive illness nor a personality disorder. $\mathrm{He}$ was competent and became physically ill before he ceased starvation.
III) ASYLUM SEEKERS/ILLEGAL IMMIGRANTS Illegal immigrants often express outrage that they have been incarcerated with criminals when the do not perceive themselves to have committed any? wrong. The sense of injustice appears to originat $\overrightarrow{\vec{E}}$ from a belief that they are entitled in some waye perhaps by family links or arranged marriages, to

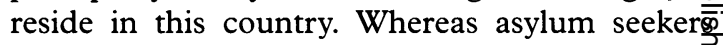
believe that their lives would be endangered $\frac{1}{2}$ returned to their country. Detainees' problems may be compounded by an inability to speak English. The necessity of interviewing through an interpreter creates additional practical and ethicat problems. The doctor must ensure that the inters preter is acceptable to the individual and respect issues of confidentiality. Few interpreters possesis relevant medical knowledge and it is not approprio ate to use relatives for this work. These factor 8 make it difficult for the doctor to judge the veracity of the information given, and hence to have confidence in the assessment of the prisoner's mental state. Whilst evidence of gross mentab illness can be detected by clinical observation early symptoms and culturally specific aspecto cannot be adequately assessed through an inter mediary as much psychiatric assessment depend $\overrightarrow{B D}$ upon the subtle nuances of language, how thifges are said and what is not said. These problems eap be overcome by working with a mental health league with relevant language skills.

At an early stage of imprisonment the motiva tion underlying food refusal in asylum seekers usually the communication of distress and the desire to change detention status. Later, following adjudication and refusal of appeals when becomes apparent to the asylum seeker that he will be repatriated against his will, hunger-strike can be motivated by the desire to die rather that accept the fate handed down to him.

I have only judged a prisoner refusing food to $b \frac{3}{6}$. mentally ill on one occasion. He was an Africa asylum seeker who had refused food since deten tion at the airport. He was a thin, frightened young man with evidence of self-neglect. Fortu nately he spoke fluent English. He believed that agents from an adjoining African country wero poisoning his food. He described visions of angels్ heard voices of a persecutory nature and reft quested a shaman, believing he had been poso sessed. Lacking insight, he did not believe that he was mentally ill and would not accept voluntar treatment. Food refusal was motivated by hics delusions and therefore a facet of his mentat disorder. Liaison with immigration authoritie and his embassy determined that he had previs ously been identified as suffering from mental ill ness in his own country. As he was acutel 
mentally unwell and his life was in danger he was detained under the Mental Health Act, $1983^{3}$ for assessment and treatment.

\section{The psychiatrist's role}

ASSESSMENT

The primary task of the psychiatrist is to determine whether the prisoner suffers from a mental disorder and to assess his competence to make the decision to refuse nourishment. She must distinguish a competent prisoner's choice to take a significant risk with his own health or the right to choose to die, from an incompetent prisoner's decision to refuse food or kill himself as part of his mental disorder.

An individual is described as being competent if he has the ability to make an informed decision, regardless of whether the decision is sensible. The comparable legal term is capacity; a patient who is judged to be unable to make decisions about his care is said to be incapacitated. Competence, or capacity, is not a concrete entity and can vary within an individual over time. Presence of a mental disorder does not always imply "incapacity". Many people suffer from a mental disorder, have a disability but still remain competent. Mental illness may reduce the individual's competence as symptoms change or become more severe. The patient may be competent to make some decisions but not others, depending upon both the degree of disability and the gravity of the decision.

As there is no objective test a dilemma arises in forming the judgment about when competence is significantly impaired and the patient becomes incompetent or incapacitated. The psychiatrist has to judge whether the patient's mental health and competence has deteriorated to such an extent that his wishes can be overruled. This decision is central to the compulsory treatment of hunger-strikers. The psychiatrist may intervene if there are grounds due to a mental state abnormality and incompetence. Incompetence due to physical deterioration, such as coma, does not allow intervention if the prisoner has previously made it clear that he does not wish to be treated in that eventuality. The concept of competence is closely related to the concept of autonomy and its attributes. Autonomy, the right to selfdetermination, is based on the principle of respect for persons and underpins the principles of civil liberty. Society does not allow interference with competent individuals' decisions, however foolish, unless the outcome places others at considerable risk of harm. Unless proven otherwise, patients are presumed to be autonomous persons capable of giving or withholding consent to treatment.

\section{Legal constraints and treatment}

Assessment of the relationship between mental disorder, incapacity and decision making is complex and is currently the subject of government consideration. ${ }^{+}$Application of existing legal definitions of mental disorder to incompetence is limited, and it is likely that law on mental incapacity will include a definition of mental disability such as "any disability or disorder of the mind or brain, whether permanent or temporary, which results in an impairment or disturbance of mental functioning".'

Any patient assessed for compulsory treatment must satisfy the psychiatrist and social worker that he not only suffers from a mental disorder, but also that the disorder is of a nature and degree which allows compulsory intervention. The patient must be at significant risk of harm to self by neglect or self-injury, or pose a significant risk to others. The criteria for compulsory treatment are defined in the Mental Health Act, $1983 .^{3}$

In the past, intervention such as the forced feeding of female suffragettes was justified on paternalistic grounds. The principle of beneficence provided the basis for "forced-cup" or tube-feeding of competent prisoners. As in all paternalistic judgments, it was felt that the doctor "knows best". Intervention was based on a greater-good argument which allowed prison authorities to override the prisoner's autonomy. At this time suicide was an offence and some doctors argued that refusal of nourishment was in itself evidence of insanity. Case law, Leigh $v$ Gladstone $^{6}$ refers to a suffragette who was forcibly fed after three days on hunger-strike. She later attempted to sue for trespass but was not successful. Lord Alverstone, Lord Chief Justice, directed the jury, saying: "... as a matter of law it was the duty of the prison officials to preserve the health of prisoners, and $a$ fortiori to preserve their lives...". ${ }^{\circ}$ Over the years there has been a change in emphasis with a shift towards protection of the individual's right to self-determination and the removal of doctors' ability to intervene against a competent patient's wishes.

Society and the law now acknowledge that a competent prisoner may choose to commit suicide by starvation. A prisoner's decision, regardless of whether it appears to be foolish, cannot be overruled unless the individual is incompetent. Government policy about force- feeding altered in 1974 when the home secretary made a statement about future prison medical policy for the assessment and management of hunger-strikers. He announced that a prison medical officer would not be neglecting his duty if he did not feed a prisoner against his will. ${ }^{7}$ Home Office procedures advise 
that when the prison doctor is satisfied a prisoner is competent he should seek an outside opinion from a psychiatrist. If the psychiatrist confirms that the prisoner is competent then the doctor is expected to advise the prisoner that he will receive medical supervision in the hospital wing and will be offered food. The prisoner must be informed that the authorities do not require the doctor to provide artificial feeding and that medical intervention will not occur unless the prisoner requests it. The home secretary's statement was followed rapidly by a response from the British Medical Association's central ethical committee, which expressed views that were neither strictly for nor against the policy change. They reminded doctors of their primary duty: “ ... the obligation of preserving human life" 8 and went on to say that competent prisoners' wishes not to be fed could be respected by doctors without fear of discipline by the General Medical Council. Currently it is not permissible for any prisoner to be treated against his will whilst detained in custody.

\section{Damages for trespass}

$\operatorname{Re} \mathrm{F}^{9}$ referred to the issue of consent to treatment. The plaintiff was a life-sentenced prisoner who brought an action against the Home Office in 1979. He claimed damages for trespass that allegedly occurred when he was treated with medication against his wishes. $\mathrm{He}$ was not refusing food. His case was dismissed as the judge found that he had consented; the Court Of Appeal upheld the judgment. In $1994 \mathrm{Re} \mathrm{R}^{10}$ determined that competent prisoners had the right to starve or dehydrate themselves to death. In contrast should a prisoner on hunger-strike also suffer from mental disorder, he can then be assessed as to whether the nature and degree of his psychiatric symptoms allows formal intervention using mental health law. The clinical rationale for force-feeding a patient with reduced competence is that food refusal is a core symptom of the disorder. In $\operatorname{Re} B^{11}$ treatment included tube-feeding as food refusal was considered to be a method of self-harm, a symptom of her mental disorder, personality disorder. Urgent transfer to hospital is allowed by a transfer direction, sections 47 and 48 , Mental Health Act, $1983,{ }^{3}$ granted by the Home Office. All prisoners must have treatment stopped, if that is their wish when they regain competence. Any intervention after they have refused treatment would be considered an assault, battery, and could result in criminal proceedings against the health care professional.

The relationship between mental illness and capacity was examined in the judgement of $R e$ C. ${ }^{12}$ The case concerns a transferred-sentenced prisoner detained in Broadmoor maximum secu禺 rity hospital. He had been transferred during senfm tence for compulsory treatment of paranoi离 schizophrenia. He later developed a gangrenous. leg ulcer and was advised to have an amputation $\overrightarrow{\mathrm{F}}$ He was told that his life was endangered and that he would only have a $15 \%$ chance of survival if the ulcer was treated conservatively. He withhelक consent, stating that he would rather die with tw. feet than live with one. Conservative treatmend continued and the operation was delayed for six. days to allow him to adjust to the prospective los? and give consent. He continued to withhold con $\overrightarrow{\overline{\bar{\epsilon}}}$ sent and the surgeon refused to act against the patient's wishes despite the belief of two consult ant psychiatrists that he was incompetent. He had further conservative operative treatment angु improved. As the hospital authority would not give the patient's solicitor an undertaking that it would not override his wishes if similar circums stances recurred she sought judicial ruling. The court heard evidence from two independent psychiatric experts in addition to the patient an $\$$ hospital staff. Predictably, medical opinion variec One independent psychiatric assessor was of th\& opinion that there were three stages in the decisio $\vec{b}$ whether to accept an operation to save life: “ (1) to take in and retain treatment information (2) to believe it and (3) to weigh that information balancing risks and needs". ${ }^{5}$ He did not identify of link between C's mental illness and his refusal to have an amputation. However, he believed that the patient's capacity to decide was reduced by his ill ness to the extent that although $\mathrm{C}$ understood the nature of the treatment he did not judge him to fulfil the second and third stages. In his opinion? the decision about whether C's competence was significantly reduced was marginal. The final decision about competence to refuse treatmer had to be made having considered the tensio between the need to respect the autonomy of patient with reduced capacity and the need $t$ \% preserve life. The surgeon judged $\mathrm{C}$ to be compe tent to withhold consent despite his mental illnes? In oral evidence $\mathrm{C}$ demonstrated active mental il $\mathrm{F}$. ness. He described himself in a deluded and grarb diose manner as an eminent doctor. Despite this he appeared to understand the nature of his physical disorder and its treatment and did nof attribute the physical disorder to a delusion. HE denied the possibility of death due to gangrene and consented to conservative treatment. Oppos? ing views were expressed by the psychiatrist responsible for the C's care who was adamant that he was incompetent. In summing up Thorpe $\vec{g}$ concluded: " . . I am completely satisfied that the presumption that $\mathrm{C}$ has the right of self 
determination has not been displaced. ... I am satisfied that he has understood and retained the relevant treatment information, that in his own way he believes it, and that in the same fashion he has arrived at a clear choice." 12 In addition to deciding that the High Court could "rule by way of injunction or declaration that an individual is capable of refusing or consenting to medical treatment" the judge ruled that his decision also applied as an advance directive. Whether the judge would have formed the same conclusions if $\mathrm{C}$ had been gravely ill and the condition had not already responded to conservative treatment is debatable. As $\mathrm{C}$ recovered with conservative treatment it may well be that the correct decision was made, but not necessarily for the right reasons.

In my submission the supporting argument advanced to justify the decision was too simplistic or perhaps even flawed. Thorpe $\mathrm{J}$ based his judgment on the premise that C's decision did involve all three stages and that his illness did not impinge on that process. However, $\mathrm{C}$ held the delusion that he was a doctor. Not only a doctor, but one of international repute who had "never lost a patient". ${ }^{12}$ This is an example of a grandiose delusion, the patient was convinced that he possessed superior abilities despite all evidence to the contrary. If $\mathrm{C}$ truly believed that he was infallible then he would have no reason to doubt his assertion that gangrene would not cause his death. $\mathrm{C}$ did not cite a connection between his complaint and the detaining authorities, that is to say he did not have a delusion about its being caused by them, neither did he believe that the suggested amputation was part of a conspiracy against him. $\mathrm{He}$ solely objected to amputation and did not believe that gangrene would cause his death. The beliefs underlying his refusal to give consent are, in my opinion, directly linked to his delusion and grandiose view of self. The illness does therefore significantly reduce his competence and he could have been overruled. An ethical argument for treatment without consent could have been advanced on the grounds of beneficence and a best interest decision by the judge and doctor for an incompetent patient.

\section{Management}

I) MENTALLY DISORDERED PRISONERS

Once detained under the Mental Health Act, 1983 and transferred to a psychiatric hospital a prisoner may be treated without consent. Treatment of the primary psychopathology should result in cessation of the hunger-strike if the food refusal was related to mental illness. The African asylum seeker was obliged to accept psychiatric treatment, however it was not necessary to use force-feeding as he started to eat shortly after taking medication. Treatment eradicated the delusions of poisoning and possession. $\mathrm{He}$ was repatriated to his family for ongoing psychiatric treatment.

\section{II) PSYCHIATRIC INTERVENTIONS WITH COMPETENT PRISONERS}

Most of my interventions with hunger-strikers were social not medical. For example, in the case of the remand prisoner, I did not believe that he was at significant risk of causing self-harm through starvation. There was evidence that he was drinking even though he stated he was not. However, it was important to facilitate change. In my experience a prisoner can get himself into an awkward situation where he continues with a hunger-strike rather than "lose face". Once engaged in a "battle of wills" with "the system" a prisoner can become immensely stubborn. Determination and the exercise of will power over the "natural" urge to eat may be the only means left of demonstrating autonomy when liberty is lost. I find it helpful to explain that, from past experience, I know that the magistrates' bench is unlikely to release a prisoner on bail if he has been judged to be a risk to himself. This intervention is usually sufficient to give the prisoner a reason to change his behaviour without loss of face.

When working with the sentenced prisoner who is distressed rather than determined to die most cases can be resolved by arranging visits by members of the family or significant others. Social support, giving prisoners access to a telephone to keep in contact with their relatives if they cannot visit frequently, and placement in a dormitory rather than a single cell can often defuse the situation. On the rare occasion when the prisoner is determined to die the episode can be aborted by discussion and grief counselling, which allow the individual to adjust to his circumstances.

Asylum seekers are often frightened people, isolated in an alien culture, unable to communicate, and may have been bullied or tortured prior to their arrival in the United Kingdom. Hungerstrike can usually be ended by simple social interventions which reduce fear, such as arranging a visit by someone who speaks his language and the visit of an appropriate minister.

\section{Additional practical and ethical dilemmas}

Apart from central issues of autonomy, competence and mental disorder, psychiatrists visiting prisons may be faced with a variety of other practical and ethical dilemmas, such as: prison 
environment; conflicting obligations; personal distress; counter-transference, and institutional illness.

\section{PRISON ENVIRONMENT}

Prison is not a therapeutic environment. Both prisoner and doctor are subject to the institution's rules and constraints. It can be difficult to establish a therapeutic relationship because the doctor may be labelled as part of the prison establishment. This issue is heightened when a mentally ill prisoner is transferred to psychiatric hospital for compulsory treatment and the doctor is perceived to be part of an abusive system, an "Agent of the State".

\section{CONFLICTING OBLIGATIONS}

The doctor may wrestle with conflicting obligations - double agency - when she has to weigh up her duty to the patient versus her duty to the institution. The primary consideration of any doctor is the duty to preserve life and minimise suffering. Prison work with competent hunger-strikers demands that the doctor suspend her primary obligation, respect the prisoner's autonomy and follow institutional rules and legal judgments.

\section{PERSONAL DISTRESS}

The psychiatrist may experience personal distress whilst observing a fellow human starve himself. As a physician trained to reduce suffering and minimise harm I find it hard to observe a prisoner who chooses to harm himself. Personal distress combined with an inability to intervene can precipitate feelings of therapeutic impotence and anger.

\section{COUNTER-TRANSFERENCE}

Staff commonly express anger about a prisoner who is refusing food. Refusal of advice and care can trigger anger in staff, who then distance themselves from the prisoner by describing him as "manipulative" or "playing up". This interpersonal dynamic can be explained by countertransference. The prisoner's hostility can be "transferred" to those responsible for his supervision and trigger subconscious negative emotions towards him. If the origin of staff's negative feelings towards the prisoner remain unconscious they will continue to feel rejected or manipulated]

INSTITUTIONAL ILLNESS

Finally, an ethical dilemma is created when a sen $\overrightarrow{\vec{F}}$ tenced prisoner becomes mentally ill and neede compulsory treatment. Custody may have trigo gered the episode of illness. ${ }^{13}$ When recovered the prisoner/patient must usually be returned t prison, which may precipitate a further episode of mental illness.

\section{Conclusion}

Food refusal by prisoners may be motivated by variety of factors, most of which are not related t $\mathrm{A}$ mental disorder. The psychiatrist has an impors tant role to play by screening for mental disordep and assessing competence. Psychiatric assessmentw and management of hunger-strikers poses diago nostic, legal, practical and ethical challenges, non of which are insurmountable. However, care must be taken to obtain all the available evidence and $t \&$ assess each case on its merits, and any actiog should be taken within legal boundaries after con sideration of ethical principles.

Bea Brockman, MB, ChB, MMEDSCI, FRCPSY is Consultant Forensic Psychiatrist, St fames'Hosp Portsmouth, Hampshire.

\section{References}

1 O'Connor A, Johnson-Sabine E. Hunger-strikers. Medicin Science and the Law. 1988:28, 1:62-4.

2 World Health Organisation. The ICD-IO classification of mentä and behavioural disorders, clinical descriptions and diagnostic guide lines. Geneva: World Health Organisation, 1992: 204.

3 The Mental Health Act, 1983. London: HMSO: 3.

4 Lord Chancellor's Department. Who decides? Making decision on behalf of mentally incapacitated adults. A consultation papep London: The Stationery Office Limited, 1997 Dec: 11-13, Cr 3803.

5 Law Commission. Mental incapacity. London: HMSO, 199 no 231 .

6 Leigh v Gladstone. The Times Law Reports. 1909 xxvi: 139-42

7 Anonymous. Artificial feeding of prisoners. British Medicat fournal 1974;3:267.

8 British Medical Association. Ethical statement - artificial feeding of prisoners. British Medical fournal 1974;3:52-3.

9 Re F [1984] 1 ALL ER: 1036-45.

$10 \operatorname{Re} \mathrm{R}$ [1994] 1 ALL ER: 677-83.

11 Re B [1994] 1 ALL ER: 683-90.

$12 \operatorname{Re} C$ [1994] 1 WLR: 291-6.

13 Salinski M. Detaining asylum seekers. British Medical fourndx 1997;314:456.

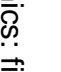

